\title{
Schistosomiasis risk factors based on the infection status among school-going children in the Ndumo area, uMkhanyakude district, South Africa
}

\author{
Muhubiri Kabuyaya $^{a *}$, Moses John Chimbaria, Tawanda Manyangadze ${ }^{a}$ and Samson Mukaratirwa ${ }^{b}$ \\ ${ }^{a}$ School of Nursing and Public Health, Department of Public Health Medicine, University of KwaZulu-Natal, Durban, South Africa \\ ${ }^{b}$ School of Life Sciences, University of KwaZulu-Natal, Durban, South Africa \\ *Corresponding author, email: muhubirikabuyaya@gmail.com
}

Background: Schistosomiasis remains a public health burden in South Africa, particularly in KwaZulu-Natal. The study aimed to identify the risk factors for transmission of Schistosoma haematobium among school-going children in the Ndumo area of uMkhanyakude district, KwaZulu-Natal.

Methods: A cross-sectional study involving 320 school-going children, aged 10-15 years, was conducted in 10 local primary schools in the Ndumo area, from May to June 2015. Data were collected using a structured questionnaire based on sociodemographic information, sanitation and water access, recreational, occupational activities, and knowledge about bilharzia. A filtration technique was used to detect $S$. haematobium eggs in $10 \mathrm{ml}$ of urine. A Chi square test, bivariate and logistic regressions were performed to assess the association between variables. Odds ratios were used to determine the strength between significant predictors with $95 \%$ confidence interval and $p$ value $<0.05$.

Results: From the 320 participants, 120 (37.5\%) were positive for Schistosoma haematobium infection. The risk factors associated with schistosomiasis were age, household head, poor sanitation, access to water source and knowledge about schistosomiasis. Conclusion: The Ndumo area is considered a moderate zone for schistosomiasis endemicity according to the World Health Organisation (WHO) classification. The significant factors identified should be considered in designing an effective schistosomiasis control program.

Keywords: children, KwaZulu-Natal, Ndumo, riskfactors, Schistosoma haematobium, Schistosomiasis, South Africa, uMkhanyakude

\begin{abstract}
Introduction
Schistosomiasis, commonly known as bilharzia, is an acute and chronic tropical disease caused by trematodes of the genus Schistosoma. ${ }^{1}$ The schistosome parasite is transmitted through a snail intermediate host with the human being the definitive host. $^{2}$ Worldwide, schistosomiasis continues to cause a public health problem with 779 million people exposed to the infection. ${ }^{3}$ The disease is present in 78 countries and endemic in 52 of those countries where an estimated $90 \%$ of people need treatment. ${ }^{4}$ Schistosomiasis has been successfully controlled in many countries but its burden remains high in Africa, particularly in sub-Saharan countries..$^{2,5,6}$
\end{abstract}

Transmission of the disease is dependent on the particular snail host, and their distribution is influenced by the environment, water development schemes and people migration. ${ }^{2}$ Humans contract infection during domestic, occupational and recreation activities that involve having contact with water infested with cercariae from the intermediate host snails. ${ }^{2,4}$ However, the movement of people from endemic areas to non-endemic areas where the snail intermediate host is present, may introduce the disease to areas where the disease had been absent. ${ }^{6}$ Insufficient and erratic rains due to climate change and the construction of water development schemes to meet power and agricultural needs are usually associated with the movement of people from both endemic and non-endemic areas into the project areas, ${ }^{4}$ thereby introducing or exacerbating the transmission of schistosomiasis. ${ }^{7}$ Schistosomiasis is more prevalent among school-going children. ${ }^{8}$ The distribution of the disease among school-going children between 10 and 15 years of age is mainly attributed to the high frequency of contact with infested water in an endemic area. This predominance thereafter decreases with less contact with infested water in adulthood., ${ }^{9,10}$
The distribution of schistosomiasis in South Africa is based on temperature suitability, which indicates that the disease is prevalent in the North West, Gauteng, Limpopo, Mpumalanga, KwaZulu-Natal and Eastern Cape provinces. ${ }^{11}$ The Limpopo, Mpumalanga and KwaZulu-Natal provinces were shown to have an estimated prevalence of $70 \%$ of the national burden in South Africa. ${ }^{11}$

The Ndumo area is located in the northern part of the uMkhanyakude district in the KwaZulu-Natal province. The area has the highest burden of schistosomiasis in the province. ${ }^{12} \mathrm{~A}$ study conducted among school children in 1998 in Ingwavuma in the same study area, reported a prevalence of $68 \% .{ }^{13}$ Another study carried out in Mtubatuba in the southern area of the district found a Schistosoma haematobium infection prevalence of $16.6 \% .{ }^{14}$ In the Ndumo area the main source of water is surface water and families rely on rivers and dams to sustain the daily household needs for water such as bathing, washing, and gardening, which expose its population, particularly schoolgoing children, to water infested with snail intermediate hosts. Therefore, school-going children are the most at risk of infection due to their activities which involve contact with water. Immigrants from Mozambique, one of the countries with the highest burden of schistosomiasis worldwide (13 456367 people requiring preventive treatment in Mozambique), ${ }^{2}$ are a threat to transmission in South Africa, ${ }^{15}$ particularly in the Ndumo area.

A better understanding of risk factors for schistosomiasis is important in controlling the disease among school children. We therefore aimed to investigate the schistosomiasis risk factors among school-going children aged between 10 and 15 years based on their S. haematobium status in the Ndumo area. The 
age group chosen has always been considered the most vulnerable to $S$. haematobium infection. ${ }^{16}$

\section{Materials and methods}

\section{Study area and population}

This study was conducted between May 2015 and June 2015 in the Ndumo area located in the northernmost part of the uMkhanyakude district in the KwaZulu-Natal (KZN) province, South Africa. The district is on the northern coast of KZN and extends over $12818 \mathrm{~km}^{2}$. It is limited to the east by the Indian Ocean, to the north by Mozambique, to the northwest by Swaziland and to the south and west by the Uthungulu and Zululand districts. ${ }^{17}$ The uMkhanyakude district is a typical rural area with a sub-tropical climate, characterised by a hot and humid summer (November - February) and a cooler and drier winter (June - August). The area is also characterised by aridness. Rivers (Ingwavuma and Pongola), streams, dams (Pongola) and ponds constitute the hydrologic network. The district is one of the poorest in the province. ${ }^{17}$ The unemployment rate was $46.18 \%$ excluding housewives in $2003,{ }^{17}$ and was reported to be $53 \%$ in $2010 .{ }^{12} \mathrm{KZN}$ has the highest prevalence of malaria, HIV infection and schistosomasis infection in the country. ${ }^{12}$ It is also the site of natural conservations, such as Ndumo reserve. ${ }^{17}$

\section{Study design and sampling}

The study was cross-sectional involving school-going children aged 10-15 years from all primary schools (10) in the Ndumo area. The study was conducted under the umbrella of a WHO/ TDR funded Malaria and Bilharzia in Southern Africa (MABISA) project. The sample size was calculated using the formula as described in Naing et al. ${ }^{18}$ as followed:

$N=Z^{2} P(1-P) / d^{2}$

where $Z$ statistic $=1.96$ for the confidence level of $95 \%$; $P$ the expected proportion in our study area $=0.8(12) ; d$ the precision $=0.05$ for $95 \%$ confidence interval. This gave us a sample size of 246 . Since there were expectations of absence of children at school during the survey and possible failures by children to return consent and assent forms, $N$ was multiplied by 2.5 to have 615 as baseline sample size of our study.

School-going children were systematically sampled using school registers in a manner that represented males and females equally in each school. Only 320 out of 615 provided both parental consent and signed assent forms and were thus eligible to participate in the study.

\section{Data collection}

\section{Parasitology survey}

Eligible children (320) participated in the parasitology screening for S. haematobium. Samples of $10 \mathrm{ml}$ of urine were collected in plastic containers during the day between $10 \mathrm{~h} 00$ and $14 \mathrm{~h} 00$ because that was when there was a high probability of obtaining larger loads of eggs. ${ }^{19}$ Urine samples were examined using the filtration technique for S. haematobium detection. ${ }^{19,20}$

\section{Questionnaire administration}

School-going children who provided parasitology samples were interviewed by pre-trained community research assistants (CRAs) under our supervision using a structured questionnaire with sections that solicited information on socio-demographic aspect, access to water and sanitation, sources of livelihood, recreational and occupational activities and knowledge about schistosomiasis. Questionnaires were prepared in English and translated to isiZulu, the main spoken local language in the area. They were pretested prior administration to ensure that content was not lost or distorted during translation. However, they were not back-translated. We relied on the experience of the translator who has been used by several other researchers within the university. The CRAs hold metric education qualifications and are proficient in both English and isiZulu.

\section{Data management and statistical analysis}

Collected data were computed and analysed using SPSS version 22 (21). S. haematobium infection was defined as any number of eggs greater than zero found in $10 \mathrm{ml}$ of urine. Pearson Chisquare test was performed to assess the association between the status of S. haematobium infection and the associated risk factors.

A bivariate logistic regression analysis based on the Crud Odds Ratio (COR) and the significance of independent variables was used to predict the likelihood of $S$. haematobium infection (positive) of the 10-15 years old school going children. Risk factors that were found to be statistically significant based on the chi-square $p$-value were considered in the bivariate logistic regression model. Adjusted Odds Ratio (AOR) and $p$-value from multivariate logistic regression model were used to investigate the strength of the likelihood of children to contract schistosomiasis. Only significant predictors from bivariate mode were included in the multivariate analysis. A 95\% confidence interval with $p$-value $<0.05$ was used at all level as the statistical significance. The dependent variable was the infection status with being positive or negative of infection as response. Independent variables were the risk factors investigated.

\section{Ethical consideration and treatment}

Ethical clearance was obtained from the Biomedical Research Ethics Committee of the University KwaZulu-Natal (BREC no: BE449/15) and gatekeeper permissions were obtained from local traditional leaders and headmasters of the targeted schools. Since the age group of our study population was between 10 and 15 years, assent and consent forms were sought and obtained respectively from school-going children and their parents. All the questionnaires and results were coded to meet the principle of confidentiality. Children found positive for $S$. haematobium infection were treated by the healthcare workers from the health department of the uMkhanyakude district.

\section{Results}

\section{Prevalence of S. haematobium}

From a total of 320 school-going children aged $10-15$ years that participated in the study, $120(37.5 \%)$ were infected with $S$. haematobium.

\section{Socio-demographic information of the participants}

Of the 320 participants, 199 (62.2\%) were females and 121 $(37.8 \%)$ were males. Out of the 120 infected school-going children, females had the higher rate of S. haematobium infection: $60.8 \%$ (73). School children aged 13 years were the most infected (25\%). Participants whose mothers were the head of the household accounted for $37.5 \%$ (45/120) of the infection. Those whose household heads were employed represented $69.2 \%$ $(83 / 120)$ infected with S. haematobium. 
Table 1: Frequencies of Schistosoma haematobium infection by gender, age, and household house in the Ndumo area of the uMkhanyakude district of South Africa

\begin{tabular}{|c|c|c|c|c|c|}
\hline \multirow[b]{2}{*}{ Factor } & & \multirow[b]{2}{*}{ Frequency } & \multicolumn{2}{|c|}{$\begin{array}{c}\text { S. haematobium } \\
\text { status }\end{array}$} & \multirow[b]{2}{*}{$p$ value } \\
\hline & & & $\begin{array}{c}\text { No. } \\
\text { Positive } \\
(\%)\end{array}$ & $\begin{array}{l}\text { No. } \\
\text { Negative } \\
(\%)\end{array}$ & \\
\hline \multirow[t]{2}{*}{ Gender } & Female & 199 & $73(60.8)$ & $126(63.0)$ & 0.699 \\
\hline & Male & 121 & $47(39.2)$ & $74(37.0)$ & \\
\hline \multirow[t]{6}{*}{ Age } & 10 years & 8 & $2(1.7)$ & $6(3.0)$ & 0.004 \\
\hline & 11 years & 84 & $26(21.7)$ & $58(29.0)$ & \\
\hline & 12 years & 81 & $20(16.7)$ & $61(30.5)$ & \\
\hline & 13 years & 67 & $30(25.0)$ & $37(18.5)$ & \\
\hline & 14 years & 44 & $22(18.3)$ & $22(11.0)$ & \\
\hline & 15 years & 36 & $20(16.7)$ & $16(8.0)$ & \\
\hline \multirow[t]{5}{*}{$\begin{array}{l}\text { Household } \\
\text { head }\end{array}$} & $\begin{array}{l}\text { Both } \\
\text { parents }\end{array}$ & 57 & $18(15.0)$ & $39(19.5)$ & 0.008 \\
\hline & Mother & 109 & $47(37.5)$ & $64(32.0)$ & \\
\hline & Father & 76 & 23(19.2) & $53(26.5)$ & \\
\hline & Others & 78 & $34(28.3)$ & $44(22.0)$ & \\
\hline & Total & 320 & $120(100.0)$ & $200(100.0)$ & \\
\hline
\end{tabular}

In the analysis, only age $(p=0.004)$, and household head ( $p=0.008$ ) were significantly associated with the infection, while the gender was not significant (Table 1).

\section{Sanitation and access to water sources for the participants}

Of 320 participants, $236(73.8 \%)$ had toilet facilities at home and accounted for $76(63 \%)$ among those carrying the infection (120). Those using pit latrines carried the biggest burden of the disease $(56.7 \%)$, followed by those without toilet facilities (36.7\%). Of the 200 school-going children that used toilets regularly $(62.5 \%$ of the participants), $50 \%$ of these children carried the disease. During the rainy season, 218 (68.1\%) children had access to clean water; but, during the dry season, 189 (59.1\%) learners went to an open source of water for their domestic needs and had a $64.2 \%$ infection rate. Participants that were involved in bathing and washing clothes at the rivers and dams during the dry season (174) had the highest rate of the disease: $86 / 120$ (71.6\%). Forty-one learners (34.25\%) who had a clean source of domestic water about $1 \mathrm{~km}$ away were more infected than those having a water source at lesser distance [less than $500 \mathrm{~m}: 28(23.3 \%)]$.

Overall, schistosomiasis had a strong relationship with the following factors: having toilet facilities at home ( $p=0.001)$, frequency of toilet use $(p=0.001)$, main source of domestic water during the rainy season $(p<0.001)$, distance of domestic water collection during the rainy season and dry season $(p<0.001)$, and bathing and washing clothes at an open source of water $(p<0.001)$.

\section{Recreational/occupational activities}

Of the 320 participants, the highest prevalence of infection was among school children not involved in swimming (83.3\%). School children who reported that they fetch water as their main occupational activity $(173 / 320)$ carried $61.7 \%(74 / 120)$ of the disease burden. A high prevalence (74.2\%) was found among children who were not watering gardens. Only those fetching
Table 2: Prevalence of Schistosoma haematobium in school-going children by recreational and occupational activities among schoolchildren in the Ndumo area of the uMkhanyakude, South Africa

\begin{tabular}{|c|c|c|c|c|}
\hline \multirow[b]{2}{*}{ Risk factors } & \multirow[b]{2}{*}{$\begin{array}{c}\text { No. } \\
\text { participants }\end{array}$} & \multicolumn{2}{|c|}{ S. haematobium status } & \multirow[b]{2}{*}{$p$ value } \\
\hline & & No. Positive & $\begin{array}{c}\text { No. } \\
\text { Negative }\end{array}$ & \\
\hline \multicolumn{5}{|l|}{ Swimming } \\
\hline Yes & 50 & $20(16.6)$ & $30(15.0)$ & 0.422 \\
\hline No & 270 & $100(83.3)$ & $170(85.0)$ & \\
\hline \multicolumn{5}{|l|}{ Fetching water } \\
\hline Yes & 173 & $74(61.7)$ & $99(49.5)$ & 0.034 \\
\hline No & 147 & $46(38.3)$ & $101(50.5)$ & \\
\hline \multicolumn{5}{|c|}{ Washing clothes } \\
\hline Yes & 142 & $53(44.2)$ & $89(44.9)$ & 0.954 \\
\hline No & 178 & $67(55.8)$ & $111(55.5)$ & \\
\hline \multicolumn{5}{|c|}{ Watering gardens } \\
\hline Yes & 89 & $31(25.8)$ & $58(29.0)$ & 0.541 \\
\hline No & 231 & $89(74.2)$ & $142(71.0)$ & \\
\hline Total & & 120 & 200 & \\
\hline
\end{tabular}

water had a statistical implication for schistosomiasis transmission $(p=0.034)$ (Table 2$)$.

\section{Knowledge about bilharzia}

In this study, 295 out of the 320 participants (92.2\%) had learnt about bilharzia, of which $108(90.0 \%)$ were observed among the infected. The highest burden (45.8\%) was found among those who had received the information about bilharzia at school. The number of children who did not know how one could get infected was 181 (56.6\%), and accounted for $42.5 \%$ (51/120) of the disease.

Knowing how one could contract bilharzia $(p=0.003)$ and knowing its symptoms were significant $(p=0.003)$. No significance was found with others risk factors.

\section{Logistic regression}

Table 3 shows the association between schistosomiasis and the risk factors. Statistical significance was found with the following factors: school children aged 11 and 12 years, having a toilet facility at home, type of toilet (pit latrine), using a toilet every time, using piped/clean water for domestic needs during the rainy season, distance to open source of water during both seasons, fetching water as occupational activity, bathing/ washing clothes at home, swimming in infested water as a mode of transmission, and knowing urinating blood (haematuria) as a symptom of schistosomiasis.

In the multivariate logistic regression analysis (Table 4), the risk factors that remained associated with schistosomiasis were the 12 year old age category, distance to open source of water less than $500 \mathrm{~m}$ during the dry season, and swimming in infested water as a way of contracting the disease. Participants whose homesteads were close to open water sources (less than $500 \mathrm{~m}$ away) were three times more likely to contract schistosomiasis [AOR 95\% Cl: 3.273(1.216-8.807)] during the dry season. Those that were aware that they could contract schistosomiasis infections by swimming in water infested with schistosomes were twice as likely to contract the disease [AOR 95\% Cl: 2.147(1.213-3.799)]. In the multivariate model, no statistical significance $(p>0.05)$ was found for the following factors: age of 
Table 3: Bivariate logistic regression analysis of the significant risk factors associated with S. haematobium in the Ndumo area, uMkhanyakude district

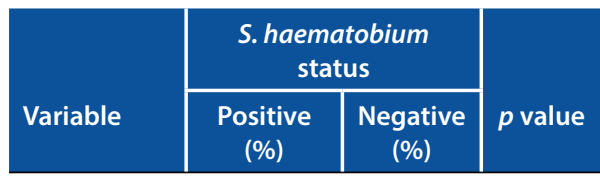

Bivariate logistic analysis

$\operatorname{COR}^{* *}(95 \% \mathrm{Cl})$

Age

\begin{tabular}{|l|c|c|c|c|}
\hline 10 years & $2(1.7)$ & $6(3.0)$ & 0.004 & $0.267(0.047-0.504)$ \\
\hline 11 years & $26(21.7)$ & $58(29.0)$ & & $0.359(0.161-0.801)$ \\
\hline 12 years & $20(16.7)$ & $61(30.5)$ & & $0.262(0.114-0.601)$ \\
\hline 13 years & $30(25.0)$ & $37(18.5)$ & & $0.649(0.287-1.465)$ \\
\hline 14 years & $22(18.3)$ & $22(11.0)$ & & $0.800(0.331-1.936)$ \\
\hline 15 years & $20(16.7)$ & $16(8.0)$ & & 1 \\
\hline Householder head & & & & \\
\hline Both parents & $18(15.0)$ & $39(19.5)$ & 0.008 & $0.585(0.280-1.220)$ \\
\hline Mother & $45(37.5)$ & $64(32.0)$ & & $0.891(0.483-1.642)$ \\
\hline Father & $23(19.2)$ & $53(26.5)$ & & $0.550(0.277-1.090)$ \\
\hline Uncle /Aunt & $4(3.3)$ & $0(0.0)$ & & $0.844(0.218-3.266)$ \\
\hline Other & $30(25.0)$ & $44(22.0)$ & & 1 \\
\hline
\end{tabular}

Toilet facilities at home

\begin{tabular}{|c|c|c|c|c|}
\hline Yes & $76(63.3)$ & $160(80.0)$ & 0.001 & $2.316(1.394-3.848)$ \\
\hline No & $44(36.7)$ & $40(20.0)$ & & 1 \\
\hline \multicolumn{5}{|l|}{ Type of toilet } \\
\hline Pit latrine & $68(56.7)$ & $156(78.0)$ & 0.001 & $0.397(0.238-0.661)$ \\
\hline $\begin{array}{l}\text { Ventilated } \\
\text { latrine }\end{array}$ & $5(4.2)$ & $1(0.5)$ & & $4.556(0.511-40.637)$ \\
\hline Other type & $3(2.5)$ & $2(1.0)$ & & $0.911(0.123-6.767)$ \\
\hline No toilet (N/A) & $44(36.7)$ & $44(36)$. & & 1 \\
\hline \multicolumn{5}{|c|}{ Frequency of using toilet } \\
\hline Sometimes & $20(16.7)$ & $23(11.5)$ & 0.000 & $0.804(0.3813-1.699)$ \\
\hline Every time & $60(50.0)$ & $140(70.0)$ & & $0.396(0.231-0.680)$ \\
\hline $\begin{array}{l}\text { Do not use } \\
\text { toilet }\end{array}$ & $40(33.3)$ & $37(18.5)$ & & 1 \\
\hline
\end{tabular}

Main source of domestic water during the rainy season

\begin{tabular}{|l|c|c|c|c|}
\hline $\begin{array}{l}\text { Piped/safe } \\
\text { water sources } \\
\text { (tap, bore- } \\
\text { hole) }\end{array}$ & $67(55.8)$ & $151(75.5)$ & 0.000 & $0.410(0.253-0.665)$ \\
\hline $\begin{array}{l}\text { Open water } \\
\text { sources (river, } \\
\text { dam, spring) }\end{array}$ & 53(44.2) & $49(24.5)$ & & 1 \\
\hline
\end{tabular}

Distance to the open source of water during the rainy season

\begin{tabular}{|l|c|c|c|c|}
\hline $\begin{array}{l}\text { Less than } \\
1 \mathrm{~km}\end{array}$ & $28(23.3)$ & $44(22.0)$ & 0.000 & $2.227(1.170-4.240)$ \\
\hline $\begin{array}{l}\text { About } 1 \mathrm{~km} \\
\text { away }\end{array}$ & $41(34.2)$ & $43(21.5)$ & & $3.337(1.812-6.146)$ \\
\hline $\begin{array}{l}\text { More than } \\
1 \mathrm{~km} \text { away }\end{array}$ & $25(20.8)$ & $22(11.0)$ & & $3.977(1.936-8.170)$ \\
\hline At home & $26(21.7)$ & $91(45.5)$ & 1 \\
\hline
\end{tabular}

Place for bathing and washing clothes during the dry season

\begin{tabular}{|l|l|l|c|c|}
\hline At home & 48(40.0) & 135(67.5) & 0.000 & $0.321(0.201-0.514)$ \\
\hline $\begin{array}{l}\text { Elsewhere } \\
\text { (river, dam, } \\
\text { spring, well) }\end{array}$ & 72(60.0) & $65(32.5)$ & & 1 \\
\hline
\end{tabular}

(Contiuned)
Table 3: (Continued)

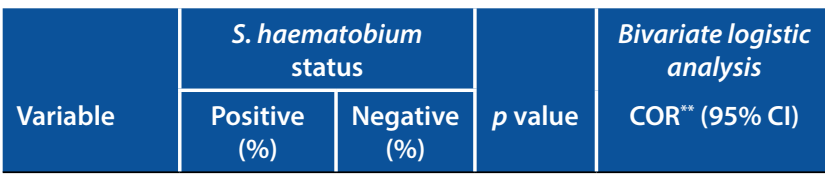

Place for bathing and washing clothes during the rainy season

\begin{tabular}{|l|c|c|c|c|}
\hline At home & $34(28.3)$ & $112(56.0)$ & 0.000 & $0.311(0.191-0.505$ \\
\hline $\begin{array}{l}\text { Elsewhere } \\
\text { (river, dam) }\end{array}$ & $86(71.7)$ & $88(44.0)$ & & 1 \\
\hline
\end{tabular}

Fetching water as occupational activity

\begin{tabular}{|l|c|c|c|c|}
\hline Yes & $74(61.7)$ & $99(49.5)$ & 0.034 & $1.641(1.035-2.602)$ \\
\hline No & $46(38.3)$ & $101(50.5)$ & & 1 \\
\hline
\end{tabular}

Transmission mode of schistosomiasis

\begin{tabular}{|l|c|c|c|c|}
\hline $\begin{array}{l}\text { Swimming } \\
\text { in infested } \\
\text { water }\end{array}$ & $32(26.7)$ & $38(19.0)$ & 0.003 & $2.147(1.213-3.799)$ \\
\hline $\begin{array}{l}\text { Drinking } \\
\text { non potable } \\
\text { water/dirty } \\
\text { water }\end{array}$ & $4(3.3)$ & $5(2.5)$ & & $2.039(.526-7.898)$ \\
\hline $\begin{array}{l}\text { Swimming + } \\
\text { drinking } \\
\text { + washing }\end{array}$ & $31(25.8)$ & $26(13.0)$ & & $3.039(1.645-5.614)$ \\
\hline Do not know & $51(42.5)$ & $130(65.5)$ & & 1 \\
\hline
\end{tabular}

Knowing the symptoms of schistosomiasis

\begin{tabular}{|l|c|c|c|c|}
\hline $\begin{array}{l}\text { Presence of } \\
\text { blood in the } \\
\text { urine (haema- } \\
\text { turia) }\end{array}$ & $40(33.3)$ & $38(19.0)$ & 0.003 & $2.462(1.430-4.239)$ \\
\hline $\begin{array}{l}\text { Pain while } \\
\text { urinating } \\
\text { (dysuria) }\end{array}$ & $4(3.3)$ & $5(2.5)$ & $1.871(0.484-7.230)$ \\
\hline $\begin{array}{l}\text { Haematuria + } \\
\text { Dysuria }\end{array}$ & $20(16.7)$ & $21(10.5)$ & $2.228(1.120-4.432)$ \\
\hline Do not know & $56(46.4)$ & $131(65.5)$ & \\
\hline Total & $120(100.0)$ & $200(100.0)$ & 1 \\
\hline${ }^{* *}$ Crude Odds Ratio. & & & \\
\hline
\end{tabular}

Table 4: Multivariate logistic analysis for risk factors associated with Schistosoma haematobium in the Ndumo area, uMkhanyakude district, South Africa

\begin{tabular}{|l|l|c|}
\hline Predictor & & AOR $(95 \% \mathrm{CI})^{* * *}$ \\
\hline Age & 10 years & \multicolumn{1}{c|}{1} \\
\hline & 11 years & $0.494(0.192-1.269)$ \\
\hline & 12 years & $0.296(0.114-0.764)$ \\
\hline $\begin{array}{l}\text { Distance to open source } \\
\text { of water }\end{array}$ & Less than 1 km & $3.273(1.216-8.807)$ \\
\hline & About 1 km away & $1.213(0.451-3.261)$ \\
\hline & More than 1 km & $1.456(0.532-3.982)$ \\
\hline $\begin{array}{l}\text { Transmission mode of } \\
\text { schistisomiasis }\end{array}$ & At home & 1 \\
\hline & $\begin{array}{l}\text { Swimming in infested } \\
\text { water }\end{array}$ & $2.147(1.213-3.799)$ \\
\hline & $\begin{array}{l}\text { Drinking dirty wa- } \\
\text { ter+washing with }\end{array}$ \\
\hline
\end{tabular}

${ }^{* * *}$ Adjusted Odds Ratio.

11 years; having an open source of water at about $1 \mathrm{~km}$ away and more than $1 \mathrm{~km}$; drinking dirty water and washing with dirty water as a mode of transmission. 


\section{Discussion}

The findings of our study revealed an overall prevalence of $37.5 \%$ (120/320) of S. haematobium among school-going children aged 10-15 years in the Ndumo area of the uMkhanyakude district. The prevalence rate met the WHO classification for an endemic area. ${ }^{22}$ Referring to the previous study done in the area, there was a notable decrease in the prevalence of $S$. haematobium; ${ }^{13}$ however, the prevalence was higher than that found in a study conducted in the southern part of the same district (Mtubatuba). ${ }^{14}$ This could be explained by the fact that after establishing that schistosomiasis was endemic in South Africa, particularly in KwaZulu-Natal, the Department of Health of KwaZulu-Natal in collaboration with the Department of Education set up a 3-year helminth control pilot program promoting regular treatment for schistosomiasis and intestinal helminth infections in all primary schools from 1997-2000. ${ }^{23,24}$

Out of the 320 participants, our study showed that females were the most affected (60.8\%). A study conducted in Nigeria found similar results, ${ }^{25}$ while others reported the opposite. ${ }^{5,26,27}$ The fact that fetching water and washing clothes are seen as being female duties in our local communities might explain the likely reason for more females being infected. In addition, the difference in the sex ratio during our sampling might have already favoured the female gender.

In our study, participants staying with their mothers as head of household were the most predisposed to develop the infection. In line with our findings, similar results were found in Tanzania. ${ }^{9}$ The fact that single mothers are usually the family providers, they spend less time with the children. Thus, the children are left on their own and may easily get involved in activities that expose them to the disease. Also, single mothers may only count on their children to get assistance for the domestic work, such as fetching water. The age group of 13 years was the most affected which was consistent with the theory that adolescents have a high contact with infested water, which decreases inversely with age in their adulthood. ${ }^{9,10}$

From our findings, participants that had a toilet at home, particularly those having pit latrines, carried the highest burden of the infection. In contrast with our findings, a study conducted in western areas of the Ivory Coast found a high rate of the infection amongst children lacking toilet facilities at their home. ${ }^{28}$ In our case, although participants had toilets at home, the open source of water (rivers and dams) remained the main source of domestic water which exposed them to the infection. Participants that had a clean source of water at their home during the rainy season were more affected $(55.8 \%)$ than those without a clean source of water (44.2\%). A noticeable increase of affected children without clean source of water at home was observed during the dry season (from $44.2 \%$ to 64.2 ). Contrary to our findings, a high rate of schistosomiasis was reported in Sudan among school children without a clean water source at their home. ${ }^{8}$ The water accumulation in boreholes and the storage of water in water tanks called "JoJo" tanks during the rainy season, may stop people from using the open water sources more often and this may explain our findings. However, due to the nonavailability of water during the dry season, people rely on rivers and dams for their daily water needs. Most of our population (68.1\%) had access to clean water during the rainy season even though the highest burden (75.5\%) was reported among those using open sources of water. In contrast with the above, the number of people having clean water during the dry season decreased while the infection rate increased among those who used open water sources. The implication of domestic water sources in S. haematobium infection has been reported by other researchers. ${ }^{8,29}$ Children with a habit of bathing and washing clothes at the rivers and dams had a high rate of the infection (71.7\%). A similar observation has been reported in other studies. ${ }^{8,28}$ In endemic areas, rivers, dams and ponds are potential sources of infection.

Our findings suggest that people fetching water from less than $1 \mathrm{~km}$ away were significantly affected. In line with this, the distance to water sources has been reported as being associated with $S$. haematobium infection in many studies.,8,30-32 The proximity to the open water source might increase the duration of exposure, giving high chances of contracting the parasite.

A high prevalence was not found among school children who practiced swimming contrary to other studies where most of the infections were found among swimmers., ${ }^{27,28}$ This may be explained by the fact that the open water sources were not appropriate for swimming compared to studies conducted in endemic areas with large surfaces of water. Most of the infected participants (61.7\%) were involved in the fetching of water. Since the study area was dry with limited piped water, fetching water for domestic use might have been the main occupational activity for school-going children, particularly females, and hence might have been a source of infection.

Our findings showed that $90.0 \%$ of those infected had knowledge about bilharzia. This was in line with the study conducted in Ethiopia $^{27}$ where, even though children were aware of the disease, the environment in which they lived remained a threat to them. They do not have a better option.

Children at puberty, toilet facilities, the main source of water, the distance to the open source of water, bathing and washing clothes at open water sources and fetching water were significantly associated with Schistosoma transmission. In accordance with our findings, previous studies reported similar observations. ${ }^{5,8,27,29,30,33,34}$ Young children living in poverty under tropical to subtropical climate have high risk to contract schistosomiasis.

\section{Conclusion}

Our study area falls into the zone with moderate risk according to the WHO classification. The population of the Ndumo area live in conditions that predispose them to contracting $S$. haematobium infection.

Improving the sanitation and access to clean water accompanied with treatment with praziquantel once every 2 years, remain the key measures for controlling the disease in the Ndumo area, uMkhanyakude district, KwaZulu-Natal, South Africa.

Acknowledgements - The authors would like to express their appreciation to Malaria and Bilharzia in Southern Africa (MABISA) team members in South Africa for field assistance. The research has been supported by the College of Health Sciences scholarship program at the University of KwaZulu-Natal and the MABISA project funded by the WHO Special Programme for Research and Training in Tropical Diseases (TDR) and the Canadian International Development Research Centre (IDRC). We thank the Southern African Science Service Centre for Climate Change and Adaptive Land Use (SASSCAL) for facilitating the writing of this manuscript with funding provided through its Task 349 initiative on capacity building. 


\section{References}

1. Mahmoud AAF. Schistosomiasis and other trematode infections. In: Kasper DL, Braunwald E, Fauci AS, et al., editors. Harrison's principles of internal medicine. 16th ed. New York: McGraw-Hill; 2006.

2. WHO. Investing to overcome the global impact of Neglected Tropical Diseases, Third WHO report on Neglected Tropical Diseases 2015. Geneva: Author; 2015. 191 p.

3. Steinmann P, Keiser J, Bos R, et al. Schistosomiasis and water resources development: systematic review, meta-analysis, and estimates of people at risk. Lancet Infect Dis. 2006;6(7):411-25. https://doi.org/10.1016/S1473-3099(06)70521-7

4. Adenowo $\mathrm{AF}$, Oyinloye $\mathrm{BE}$, Ogunyinka $\mathrm{BI}$, et al. Impact of human schistosomiasis in sub-Saharan Africa. Braz J Infect Dis. 2015;19(2):196-205. https://doi.org/10.1016/j.bjid.2014.11.004

5. Kapito-TemboAP,MwapasaV,MeshnickSR,etal.Prevalencedistribution and risk factors for schistosoma hematobium infection among school children in Blantyre, Malawi. PLoS Negl Trop Dis. 2009;3(1):e361-70. https://doi.org/10.1371/journal.pntd.0000361

6. Chitsulo L, Engels D, Montresor A, et al. The global status of schistosomiasis and its control. Acta Tropica. 2000;77(1):41-51. https://doi.org/10.1016/S0001-706X(00)00122-4

7. Chimbari M, Chirebvu E, Ndlela B. Malaria and schistosomiasis risks associated with surface and sprinkler irrigation systems in Zimbabwe. Acta Tropica. 2004;89(2):205-13. https://doi.org/10.1016/j. actatropica.2003.09.015

8. Abou-Zeid AH, Abkar TA, Mohamed RO. Schistosomiasis infection among primary school students in a war zone, Southern Kordofan State, Sudan: a cross-sectional study. BMC Public Health. 2013;13(1): $1-8$.

9. Verani JR, Abudho B, Montgomery SP, et al. Schistosomiasis among young children in Usoma, Kenya. Am J Trop Med Hyg. 2011;84(5):78791. https://doi.org/10.4269/ajtmh.2011.10-0685

10. Colley D, Secor W. Immunology of human schistosomiasis. Parasite Immunol. 2014;36(8):347-57. https://doi.org/10.1111/pim.2014.36. issue-8

11. Moodley I, Kleinschmidt I, Sharp B, et al. Temperature-suitability maps for schistosomiasis in South Africa. Ann Trop Med Parasitol. 2003;97(6):617-27. https://doi.org/10.1179/000349803225001445

12. Lankford B, Pringle $C$, Dickens $C$, et al. The impacts of ecosystem services and environmental governance on human well-being in the Pongola region, South Africa. London, Norwich and Pietermaritzburg: Report to the Natural Environment Research Council, University of East Anglia and Institute of Natural Resources; 2011. Available from: http:// www.uea.ac.uk/dev/prespa/FINAL+UEA+Prepsa+NERC+Report++April.2010;18.

13. Saathoff $E$, Olsen A, Magnussen P, et al. Patterns of Schistosoma haematobium infection, impact of praziquantel treatment and re-infection after treatment in a cohort of schoolchildren from rural KwaZulu-Natal/South Africa. BMC Infect Dis. 2004;4(1):1-10. https://doi.org/10.1186/1471-2334-4-40

14. Daniel AK. Spatial analysis of Schistosoma haematobium infection among school children in a rural sub-distrrict of South Africa: an application of geographical information system. Johannesburg: University of the Witwatersrand; 2009.

15. Appleton C, Ngxongo S, Braack L, et al. Schistosoma mansoni in migrants entering South Africa from Mocambique-a threat to public health in north-eastern KwaZulu-Natal? S Afr Med J-Suid-Afrikaanse tydskrif vir geneeskunde. 1996;86(4):350-3.

16. Abed Elhadi $A$, Talaat $M$, Gibod $M$, et al. Histological assessment of tissue repair after treatment of human schistosomaisis. schistosomaisis in the past. Transmission Phase-Acta-Tropic. 2000;77:90-6.
17. Haley Sharpe Southern. Africa (Pty) Ltd. uMkhanyakude District Municipality: Local Economic Development Initiative. Institute of natural resources. 2003. Accessed 2015. Available from: http://www. led.co.za/sites/default/files/umkhanyakude_led_report.pdf

18. Naing L, Than W, Rusli B. Practical issues in calculating the sample size for prevalence studies. Arch Orofac Sci. 2006;1(1):9-14.

19. WHO. Basic laboratory methods in medical parasitology. Geneva: Author; 1991.

20. Cheesbrough M. Laboratory-practice-in-tropical-countries-part-1. 2009;2.

21. IBMC. IBM SPSS statistics for windows, version 22.0. Armonk, NY: Author; 2013.

22. Crompton DWT. Preventive chemotherapy in human helminthiasis: coordinated use of anthelminthic drugs in control interventions: a manual for health professionals and programme managers. Geneva: World Health Organization; 2006.

23. Appleton C, Kvalsvig J. A school-based helminth control programme successfully implemented in KwaZulu-Natal. South Afr J Epidemiol Infect. 2006;21(2):55-67.

24. Randjelovic A, Frønæs S, Munsami M, et al. A study of hurdles in mass treatment of schistosomiasis in KwaZulu-Natal, South Africa. South African Family Practice. 2015(ahead-of-print):1-5.

25. Oluwasogo OA, Fagbemi OB. Prevalence and risk factors of Schistosoma haematobium infections among primary school children in Igbokuta Village, Ikorodu North Local Government, Lagos State. Nurs Health Sci. 2013;2:62-8.

26. Augusto G, Nala R, Casmo V, et al. Geographic distribution and prevalence of schistosomiasis and soil-transmitted helminths among schoolchildren in Mozambique. Am J Trop Med Hyg. 2009;81(5):799803. https://doi.org/10.4269/ajtmh.2009.08-0344

27. Geleta S, Alemu A, Getie S, et al. Prevalence of urinary schistosomiasis and associated risk factors among Abobo Primary School children in Gambella Regional State, southwestern Ethiopia: a cross sectional study. Parasites \& Vectors 2015;8(1):1 106-14. https://doi.org/10.1186/ s13071-015-0822-5

28. Matthys B, Tschannen AB, Tian-Bi NT, et al. Risk factors for Schistosoma mansoni and hookworm in urban farming communities in western Côte d'Ivoire. Trop Med Int Health. 2007;12(6):709-23. https://doi. org/10.1111/tmi.2007.12.issue-6

29. Bala A, Ladan M, Mainasara M. Prevalence and intensity of urinary schistosomiasis in Abarma village, Gusau, Nigeria: A preliminary investigation. Scientific World J. 2012;7(2):1-4.

30. Clennon JA, Mungai PL, Muchiri EM, et al. Spatial and temporal variations in local transmission of Schistosoma haematobium in Msambweni, Kenya. Amer J Trop Med Hygiene. 2006;75(6):1034-41.

31. Opara K, Udoidung N, Ukpong I. Genitourinary schistosomiasis among pre-primary schoolchildren in a rural community within the Cross River Basin, Nigeria. J Helmintho. 2007;81(04):393-7.

32. Rudge JW, Stothard JR, Basáñez M-G, et al. Micro-epidemiology of urinary schistosomiasis in Zanzibar: local risk factors associated with distribution of infections among schoolchildren and relevance for control. Acta Tropica 2008;105(1):45-54. https://doi.org/10.1016/j. actatropica.2007.09.006

33. Augusto G, Magnussen P, Kristensen TK, et al. The influence of transmission season on parasitological cure rates and intensity of infection after praziquantel treatment of Schistosoma haematobium-infected schoolchildren in Mozambique. Parasitol. 2009;136(13):1771-9. https://doi.org/10.1017/S0031182009006210

34. Krauth SJ, Musard CC, Traoré SI, et al. Access to, and use of, water by populations living in a schistosomiasis and fascioliasis co-endemic area of northern Côte d'Ivoire. Acta Tropica. 2015;149(1):179-85.

Received: 11-03-2016 Accepted: 25-11-2016 